\title{
Rare-earth-free propulsion motors for electric vehicles: a technology review
}

\author{
Jordi-Roger Riba ${ }^{1}$, Carlos López-Torres ${ }^{2}$, Luís Romeral $^{2}$, Antoni Garcia ${ }^{3}$ \\ ${ }^{1}$ Escola d'Enginyeria d'Igualada (EEI-Escola d'Adoberia), Universitat Politècnica de Catalunya, Electrical Engineering \\ Department, Pla de la Massa 8, 08700 Igualada (Catalunya, Spain), Tel. +34 938035300, Fax +34 938031589. E-mail: \\ jordi.riba@eei.upc.edu \\ ${ }^{2}$ Universitat Politècnica de Catalunya, Electronic Engineering Department, Rambla Sant Nebridi, 22, 08222 Terrassa \\ (Catalunya, Spain) \\ ${ }^{3}$ Universitat Politècnica de Catalunya, Electrical Engineering Department, Rambla Sant Nebridi, 22, 08222 Terrassa (Catalunya, \\ Spain)
}

Abstract - Several factors including fossil fuels scarcity, prices volatility, greenhouse gas emissions or current pollution levels in metropolitan areas are forcing the development of greener transportation systems based on more efficient electric and hybrid vehicles. Most of the current hybrid electric vehicles use electric motors containing powerful rare-earth permanent magnets. However, both private companies and estates are aware of possible future shortages, price uncertainty and geographical concentration of some critical rare-earth elements needed to manufacture such magnets. Therefore, there is a growing interest in developing electric motors for vehicular propulsion systems without rare-earth permanent magnets. In this paper this problematic is addressed and the state-of-the-art of the electric motor technologies for vehicular propulsion systems is reviewed, where the features required, design considerations and restrictions are addressed.

Keywords -Electric vehicles, hybrid electric vehicles, electric motors, rare-earth elements, permanent magnets.

\section{INTRODUCTION}

Fossil fuel price uncertainty, resources scarcity and greenhouse gases emissions (GHG) are forcing the current energy system to be based on more efficient, sustainable and renewable technologies [1,2]. The transportation sector is one of the main oil users, consuming almost half of the oil resources [3], so it is especially sensible to supply disturbances and price volatility. Road transport accounts for roughly $75 \%$ of transport GHG emissions [4]. This is forcing the transportation sector to improve due the need of enhanced efficiency [5], reduce the dependency on foreign resources and lower GHG and noise emissions [3]. The use of green transportation systems is of paramount importance in modern cities due to the current pollution levels, environmental issues and severer emission standards for vehicles [6]. One of the greatest challenges is to develop near zero-emission vehicles [7]. Automotive electrification is experiencing a notorious increase since this technology allows facing most of the aforementioned issues [3,8]. Therefore power electronics devices, and propulsion and energy storage systems for electric vehicles are receiving much attention [9]. It is worth noting that with the growing installation of fluctuating power generation systems based on renewable energy sources (RES), in both generation and demand sides, more flexibility is required and electric vehicles can help to balance this fluctuation on the demand side [10,11].

Features required for electric propulsion motors include high efficiency, high torque and power per unit volume, that is, compactness, [12] good dynamic response, simple construction and high reliability (brushless operation). To achieve these challenging requirements, the state-of-the-art technologies for new generation of propulsion systems for electric vehicles with improved features is currently based on different materials, including soft magnetic laminations and rare-earth elements (REEs) [2], among which rare-earth neodymium magnets (NdFeB) [13] highlight. In addition progresses in power and control electronics, and design and analysis systems based on finite element methods [5] highly impact these technologies.

In recent years rare-earth permanent magnet machines have gradually replaced traditional motors and 
generators in many applications [14], including automotive drives, wind generators or home appliances since they exhibit enhanced efficiency and power density [15-17]. As an example, modern low-speed direct drive generators for wind turbines have a rare-earth magnet content of around $650 \mathrm{~kg} / \mathrm{MW}$ [18]. This had led to concerns of rapid depletion of REEs resources [2]. It is widely recognized that there is a geographical concentration of the REEs resources [19], since today China is the predominant supplier [20], with about $96 \%$ of the REEs' worldwide production [19,21], [21] although it has less than $40 \%$ of the proved reserves [22]. Although new mines are planned, they take several years to be productive $[1,20]$. In 2011, REEs products experienced a sudden price rise of about 600 percent due to reductions in export quotas from China [23]. According to [24], the current price of some REEs is too low to reflect their value, does not represent the shortage of the resources and does not compensate the environmental damage. An interesting option consists in recycling and reusing REEs, since it can help in reducing the total amount of primary rare-earth mineral to be used. However, REEs recycling rates are still extremely low, less than $1 \%$ [22]. Due to the multiple uses of REEs, their demand is expected to increase considerably in the future [19], so the risk of a limited supply chain is a focus of concern [25]. According to the European Commission [26] and the US Department of Energy (DOE) [27], some REEs are considered critical for the respective economies, since they can place regional industries in a vulnerable situation due to possible shortages or even to an imminent risk of supply interruption [28], and some of them, and especially dysprosium, show symptoms of serious scarcity [18]. Dysprosium and other REEs are often added to the NdFeB formulations to enhance their coercivity [14,29].

The cost of permanent magnets (PMs) can significantly determine the final cost of PM motors used in electrical propulsion applications [30]. Due to the above-described economic, environmental and geopolitical issues, nowadays there is a growing need to produce efficient electric motors which do not use rare-earth PMs [31]. Therefore the automotive industry is exploring different technologies based on environmentally friendly and available materials.

This paper reviews the state-of-the-art in electric motors technology without rare-earth PMs for vehicular propulsion systems. The paper intends to make a comprehensive review of the most popular technologies under research or under development/application, thus identifying the strong and weak points of each technology and the challenges to be faced. A comparative analysis based on the torque density, machine constant of mechanical power and maximum efficiency of the different technologies is also performed, which is based on data published in recent scientific publications.

\section{RARE-EARTH MATERIALS FOR PERMANENT MAGNETS}

This section reviews the rare-earth materials commonly used for PMs in electrical rotating machines, their main features and environmental issues.

Rare-earth elements (REEs) are more abundant in the earth's crust than the name suggests [32], since the name refers to the historical difficulties in identifying and purifying REEs [2], although some heavy REEs are less common [33]. However, REEs mining is only cost-effective in a limited number of locations due to the separation complexity and the ore grade of the deposits [32]. REEs mining also produces environmental problems such as the ones related to the radioactive minerals associated with REEs [33].

REEs have a wide range of applications, including automobile and petroleum refining catalysts, fiber optics, electronics, lamp phosphors for color flat panel displays, compact electric motors for electric vehicles (EVs) or direct drive generators for wind power applications [1,21]. REEs are key elements in the change to a low-carbon greener economy [22]. According to the IUPAC there are 17 REEs (scandium, yttrium and the 15 lanthanides) [1,22,34,35] from which samarium (Sm), terbium $(\mathrm{Tb})$, neodymium $(\mathrm{Nd})$ and dysprosium (Dy) highlight to manufacture high performance PMs. The last two elements are of especial importance to produce PMs for efficient and compact electric propulsion machines. Although neodymium is quite common, dysprosium is one of the rarest ones [32]. Samarium cobalt magnets exhibit 
higher operating temperature than neodymium magnets (NdFeB) [36] but neodymium magnets offer the maximum energy product, a measure of the capacity to retain and provide magnetic flux [21], so they exceed the magnetic properties of samarium cobalt magnets [35].

PMs can be classified in three main groups, i.e. alnico, ferrite and rare-earth magnets. However, the PMs market splits approximately 2:1 between neodymium and hard ferrite magnets, whose costs are in a proportion of more than 25:1 [37].

Alnico magnets mainly contain aluminum, nickel, cobalt, iron, and some grades may also include copper and titanium or other elements like silicon or zirconium [38]. These magnets exhibit high remanent magnetic induction $B_{r}$ and allow high temperature operation. However, they can be easily demagnetized because of the low coercive field $H_{c}$ [39]. Worldwide there is a reduced but stable demand for this kind of magnets [37].

Ferrite magnets, also known as ceramic magnets, are mainly composed of ferric oxide, which is abundant in supply, but they may also contain strontium or barium or a combination of both elements [39]. The most common formulations are $\mathrm{SrFe}_{12} \mathrm{O}_{19}$ and $\mathrm{BaFe}_{12} \mathrm{O}_{19}$. Ferrite PMs also present a very high electric resistivity, therefore minimizing eddy current losses when used in electric motors but they present a low energy product $(\mathrm{BH})_{\max }$. Ferrites are inexpensive magnets [38], quite easy to produce and represent roughly one-third of the PM sales [37]. The remaining two-thirds are mostly rare-earth PMs. Ferrite magnets are the best placed candidates to replace $\mathrm{NdFeB}$ magnets in rare-earth-free electric motors for EVs.

Samarium cobalt magnets are rare-earth magnets which, apart from samarium and cobalt, may also contain zirconium and iron. They are often classified into two categories, $\mathrm{SmCo}_{5}$ and $\mathrm{Sm}_{2} \mathrm{Co}_{17}$, which are referred to as 1:5 and 2:17 [39]. It is estimated that about 5\% of the total trade of rare-earth magnets belong to the samarium cobalt family [37].

Neodymium-iron-boron magnets, known as $\mathrm{NdFeB}$, are the most popular [18] and powerful PMs, so they are the most used in electric machines. Since iron and neodymium are relatively abundant, these magnets have similar or lower cost than samarium cobalt magnets. Neodymium alloys usually are composed of two rare-earth elements parts (essentially neodymium with possibly a minor substitution of dysprosium, praseodymium or terbium) to 14 iron parts and one boron part [39]. The addition of praseodymium in combination with or substituting neodymium, as well as dysprosium and terbium allows increasing the operating temperature [18,27], although the addition of these elements can decrease the magnetization of $\mathrm{NdFeB}$ magnets. However, the supply situation of both dysprosium and terbium is precarious, as reflected by the market price, which is 9 and 15 times that of neodymium [40], respectively, since these two REEs are among the most critical elements in terms of supply risk [19,40,41] although some studies reveal that the exhaustion of their reserves is not an imminent concern [2].

Table 1 shows some of the most important physical properties of the main types of PMs according to [39]. Since each magnet category has different compositions, each property has a range of values.

\section{HERE TABLE 1}

\section{ELECTRIC VEHICLES (EVs) ARCHITECTURES}

The concept of EV is not new but came back in the late 1990s [42]. An electric vehicle (EV) is any vehicle whose driving power is partially or totally supplied from an onboard battery pack [11]. There are three main types of EVs, that is, hybrid electric vehicles (HEVs), plug-in electric vehicles (PHEVs) and full electric vehicles (FEVs) [4] whose main configurations are shown in Fig. 1.

\section{HERE FIGURE 1}

EVs with energy storage capacity allow operating in the regenerative braking mode, thus converting some of the kinetic energy lost during braking or coasting into electricity, which is stored in the battery. 
The stored energy is later used to power the motor whenever the vehicle operates in electric mode. By this way the driving range can be increased by 10-25\% [8]. Since ICE-powered vehicles are less efficient than EVs, the latter ones allow to significantly reduce the operating costs [8]. PEVs and FEVs allow recharging the battery externally from the grid [11], thus increasing energy conversion efficiency and lowering GHG emissions with respect to HEVs, since they both improve when increasing the charge depleting mode range [43]. FEVs are fully powered by the grid, so they operate in the battery depleting mode, thus requiring a larger battery pack, whereas in HEVs and PHEVs the ICE can act as a back-up to recharge the battery pack or to propel the vehicle directly or in combination with the electric motor. FEVs offer lesser travelling range, mainly because the price and weight limitations of current battery technology. Due to the presence of the ICE and the electric motor/generator, HEVs and PHEVs are more complex and include more components than FEVs, therefore requiring more compact electric motors/generators.

\section{ELECTRIC MOTOR REQUIREMENTS FOR EVS}

It is well-known that for a given rated power, high speed motors provide a lower shaft torque, thus requiring less iron and copper since they generate a lower magnetic flux and torque. Therefore high speed motors have reduced weight and size compared to low speed machines [44].

Electric machines for EVs propulsion systems require different characteristics than those commonly used in industrial processes. For example, EVs perform frequent starts and stops, need high acceleration rate for fast starting and capability to work in harsh environments [6]. Motor drives for EVs require high efficiency over a wide speed and torque region, high torque and power densities, fast dynamic response, simple construction, high reliability [12], reasonable cost, regenerative braking capability, good controllability and low acoustic noise. Fault tolerant capability is also an essential issue [44]. Therefore, motor drive requirements for EVs include high torque at low speed for fast starting, and high power at high speeds for cruising. For urban driving it is also necessary high efficiency in the low torque and low speed region [45]. Low rotor inertia and smooth torque are also valuable, since low inertia allows making the driving more comfortable, especially for direct drive motors, whereas a smooth torque reduces vibrations and wear in mechanical components [9]. The torque-speed characteristic (see Fig. 2) of the motor greatly affects vehicle performance.

\section{HERE FIGURE 2}

As shown in Fig. 2, the motor can provide the rated torque up to the rated or base speed, thus reaching the rated power. Beyond the base speed, the operation is limited by the constant power speed range (CPSR) region. The extension of the CPSR region depends on the motor technology, the particular motor design and the applied control strategy [44]. An extended constant power region allows reducing the rated power of the motor and consequently its weight. Therefore a wide CPSR is desirable, but at the expense of passing performance at high-speed. Motors with a wide CPSR region perform better at higher speeds whereas motors with a narrow constant power region perform better at lower speeds since they can accelerate very fast from standstill [46]. According to [44] a ratio of maximum speed to base speed of 5-6 minimizes the power rating while maximizing regenerative braking capability and acceleration performance.

Other requirements include the use of environmentally friendly materials and simple manufacturing processes. As explained, it is also important to use available and environmentally friendly materials [47] with no supply risk, therefore it is desirable to replace REEs in motors using PM materials. To this end, motors based on ferrite PMs are under research and development. The challenge is to design rare-earth-free motors which are competitive with rare-earth PM motors in terms of efficiency and torque-speed characteristic.

DC motors have been used in EVs propulsion systems, mainly due to its simple control and high starting torque [6]. Conventional DC motors are brushed machines including coils in the stator and rotor excitation. 
The armature windings in the rotor are supplied through the mechanical commutator which is in contact with the brushes and acts as a rotary switch. However, the windings in the rotor generate power losses, the commutator requires periodic maintenance, especially in harsh environments, being this is a critical issue in EVs. The extra losses in the rotor reduce the efficiency of these machines while limiting the power density since rotor cooling is always more challenging than stator cooling. Traditional brushed DC motors also generate sparks that are dangerous in hazardous atmospheres.

Wound rotor synchronous motors (WR-SMs) have been widely applied in many applications. They usually have a three-phase winding in the stator and a DC field excitation winding in the rotor which allows operating in the field weakening region, thus easily extending the CPSR. Traditional WR-SMs require brush slip rings to supply the rotor excitation, thus producing rotor losses, so cooling may be critical and the power density must be lowered to deal with the rotor losses [9].

Brushed DC motors were widely used in variable-speed industrial applications before the development and commercialization of power electronics [48], however they were replaced by AC motors in many applications. At the end of the nineties some commercial FEVs were powered by DC motors, for example Renault Express and Renault Clio with a very limited volume of production [49].

Wound rotor synchronous motors (WR-SMs) have been applied in commercial FEVs such as Renault Kangoo I (2001-2003) although FEVs driven by WR-SMs are still being commercialized, for example Renault ZOE and Renault Fluence [48,50,51].

Therefore, both brushed DC motors and WR-SMs are not analyzed in this paper since they don't meet the efficiency and power density requirements for EVs propulsion systems [9]. Therefore, brushless motors are more desirable than brushed machines for this application.

Table 2 shows a comparative analysis of the most used electric motors for vehicular propulsion systems, that is, induction motors (IMs), rare-earth PM synchronous motors (PMSMs) and switched reluctance motors (SRMs), which compares features such as the efficiency, weight, cost or efficiency among others [44,52]. However Table 2 does not consider factors such as materials' availability and supply risk as discussed in this paper.

\section{HERE TABLE 2}

Results summarized in Table 2 clearly show that the brushed DC motor is the one with lowest score.

It is well-known that PM motors can be subjected to demagnetization problems as stated in several works $[16,17,53,54]$, therefore this issue must be contemplated during the design stage by selecting suitable PM materials and by means of an appropriate magnetic design.

Some strategies to increase torque and power densities in different motor types is reported in [55], which include the use of concentrated windings in PM synchronous motors, an increase of the DC bus voltage, the application of improved cooling systems or the use of reluctance torque, which is cost-effective and contributes to reduce the no-load losses, since it provides low magnetic flux. In addition, the use of power electronic devices based on silicon carbide or gallium nitride allow increasing the operating temperature, so the current density of the windings can be increased and therefore the torque density. In [55] it is stated that by applying these strategies rare-earth-free motors can achieve similar torque and power density than those of current rare-earth PM motors.

\section{ELECTRIC MOTORS WITHOUT RARE-EARTH PMS}

In this section the electric motors summarized in Fig. 3 are reviewed.

\section{HERE FIGURE 3}

\subsection{Squirrel cage induction motors (SCIMs)}

Squirrel cage IMs (SCIMs) are brushless alternating current (AC) machines fed by sinusoidal voltagescurrents, which are widely applied in industrial applications and for electrical propulsion systems [6,56] 
since they offer high simplicity, low cost, reliability, robustness, low torque ripple, low maintenance needs and ability to operate in harsh environments. SCIMs are being applied in some commercial FEVs including electric cars, buses and light trucks [9]. Some examples of electric cars driven by SCIMs are the Tesla S2014, Tazzari Zero, Mercedes-Benz B-Class Electric Drive, Mahindra e2o [51], Toyota RAV4 [55]. Other examples are the Newton light electric truck from Smith Electric Vehicles that in the first version was equipped with a three-phase SCIM [57] or the Optare solo EV battery electric bus [58].

SCIMs are asynchronous machines, that is, the speed of the rotating field generated by the stator windings and the rotor speed are different. SCIMs have a simple structure compared with other motor types, which facilitates the design and manufacture [57]. In addition they don't use any type of PM but cheaper materials. Although three-phase SCIMs are the most habitual, motors with higher number of phases are being developed since they allow increasing power density, reducing torque pulsations and the current per phase [58]. The rotor contains a cast aluminum cage in which the rotor currents are induced by the rotating magnetic field generated by the stator windings. The interaction between the rotating magnetic field and the magnetic field generated by the rotor currents produces the electromagnetic torque. Efficiency can be boosted by using rotor bars and end rings of copper instead of aluminum [59,60]. Fig. 4 shows the cross-section of a SCIM.

\section{HERE FIGURE 4}

SCIMs present inherent drawbacks, including difficult control at low speed operation, low power factor under light load conditions, high starting currents [3], low efficiency and low inverter usage [6]. The magnetization current, which is absorbed even under no-load conditions, increases copper losses and the rating of the electronic converter [9]. By applying suitable control techniques, the maximum torque can be attained during starting while keeping starting current low. SCIMs can also be applied in in-wheel applications by using an outer cage rotor, thus increasing the air gap diameter and therefore the output torque [61]. It is notorious that SCIMs have lower torque density and less efficiency than other motor types [57]. Therefore, SCIMs are more applied in FEVs than in HEVs or PHEVs due to the space restrictions imposed by the latter two types of vehicles. The maximum speed is usually limited to10000 r/min [44]. By applying flux weakening techniques, the constant power range can be extended up to 4-5 times the base speed, which is a key requirement for EVs [6].

Different speed and torque control techniques are being applied. The simpler of them is the scalar control, which changes the magnitude and the frequency of the phase voltages. However, its performance under transient conditions is limited. To improve performance during transient conditions, field oriented control (FOC) and direct torque control (DTC) are being applied, although sensorless control methods, that is, drives without a speed or position sensor, are receiving much attention.

\subsection{PM brushless motors}

PM brushless motors can be categorized as brushless DC (also known as BLDC motors) and brushless AC (also known as PM synchronous machines or PMSMs) [6]. Both PMSMs and BLDC machines have a permanent magnet rotor, but they present a different stator winding arrangement. BLDC motors are trapezoidally wound, have a trapezoidal back-EMF [62] and are often fed by rectangular-shaped phase currents. This allows applying a very simple control method by using a position feedback strategy that senses the rotor just six times each revolution [62]. BLDC motors evolved from brushed DC motors in order to remove the commutator and the brushes. BLDCs can be understood as inverted DC machines, since the rectangular shaped currents are applied to the stator (in a brushed DC machine the rotor currents are approximately rectangular), whereas the field excitation is transferred to the rotor, which is generated by means of PMs. PMSMs are an evolution of the wound rotor synchronous machines, in which the field winding with the brushes and slip rings are replaced by PMs. The stator of a PMSM is very similar to that of the induction machine. PMSMs are sinusoidally wound, generate a sinusoidal back-EMF [63] and are 
fed by sinusoidal currents [46]. These differences with respect to BLDC motors lead to important differences in both the motor drive behavior and the control algorithms to be applied, so PMSMs present better features for EVs traction systems.

Although typical PM machines have radial field design, axial field designs can offer certain advantages in some power ranges in regards to torque-to-inertia ratio and power density [63]. Axial flux designs are also preferred for in-wheel applications.

PMSMs have been widely applied in EVs propulsion systems. However, in most of the applications rareearth PM are used [64,65] because of their superior magnetic properties, although PMSMs with high efficiency can be designed with low magnet mass [66]. Rare-earth PMSMs exhibit appealing features including high power and torque densities, synchronous speed, high efficiency, precise torque control or maintenance free operation [54,67]. However, PMSMs present some drawbacks such as limited field weakening capability that restricts the constant power region, which is especially notorious in surface mounted PMSMs (SPMSMs) machines and less critical in machines with interior PMs (IPMSMs), or possible demagnetization problems induced by mechanical impacts, high temperature rises or short circuit effects. Therefore both safety [46] and fault tolerant operation [6] are critical issues.

Fig. 5 shows two IPMSMs with tangentially and V shaped embedded PMs.

\section{HERE FIGURE 5}

Compared to surface magnets, interior magnets are more protected, both mechanically and magnetically. Therefore, IPMSMs are more robust and often use more PMs than SPMSMs. IPMSMs generate higher flux density in the air gap and are more applied for extended constant power operation [6]. However, this solution presents a higher cost due to manufacturing difficulties and may reduce the maximum allowable speed [46]. IPMSMs present an inherent saliency which provides the machine a supplementary reluctance torque, thus improving motor performance [9].

The torque in PMSMs has two components, the reluctant torque which is due to the saliency, and the alignment torque due to the interaction between the magnetic field generated by the stator currents and the PMs in the rotor. The saliency is measured by means of the ratio $L_{d} / L_{q}$ between the direct-axis and the quadrature-axis inductances [68]. SPMSMs present similar direct and quadrature axis inductances, $L_{d} \approx L_{q}$, as the permeability of the PMs is almost that of air [63], whereas in IPMSMs the saliency ratio can typically be in the range $L_{d} / L_{q} \approx 1.5-2.5$ [9]. When $L_{d} \neq L_{q}$ a reluctance torque is generated which adds up to the alignment torque, thus increasing the total torque, the torque density [63] and extending the CPSR as occurs in IPMSMs [68].

Nowadays, rare-earth IPMSMs are possibly the most used machines in EVs [69] since the use of rareearth magnets allows lighter motors with enhanced torque and power densities, higher efficiency and suitability for sensorless control because of its rotor saliency [70]. However, the weight of rare-earth PMs deeply impacts the cost of propulsion motors for EVs [55]. When using rare-earth PMs, the supply risk and high cost of rare-earth PMs can be critical issues. Therefore, many efforts are underway to develop rareearth-free motors to substitute IPMSMs [71,72]. The key points in designing rare-earth-free motors are the power and torque densities and the efficiency.

Ferrite magnets are being deeply studied to replace rare-earth magnets. Ferrite PMs have much lower electrical conductivity than $\mathrm{NdFeB}$ magnets, therefore presenting very low losses due to eddy currents, thus reducing demagnetization occurrence [71]. However, ferrite magnets have much lower residual induction field and maximum energy product than $\mathrm{NdFeB}$ magnets, so ferrite magnets cannot directly replace $\mathrm{NdFeB}$ magnets in PM machines because they generate much less magnetic flux density [68]. Despite of these facts, in [73] two axial flux ferrite PM motors are claimed to be competitive in terms of torque/power density and efficiency with respect the rare-earth PM motor of the Toyota Prius 2010 HEV. In [73] it is also stated that PMSMS with ferrite PMs are most well-suited to replace rare-earth PM motors than 
induction motors or SRMs. Other authors are developing PMSMs based on ferrite PMs for electric traction applications, and it seems that there is a tendency of using axial flux machines, especially for in-wheel applications [74-77].

Nowadays, most of the commercial FEVs are driven by PMSMs. Some examples are the BMW i3, Nissan Leaf, Volkswagen e-Golf, Mitsubishi i-MiEV, Volkswagen e-UP, Citroën C-Zero, Peugeot iOn, Citroën Berlingo Electric, Ford Focus Electric, Fiat 500e, Bolloré Bluecar, Chevrolet Spark EV, Kia Soul EV, Mercedes-Benz Vito E-Cell or Smart fortwo ED among others [51]. Although most of them are based on rare-earth motors, the tendency is to minimize the permanent magnet content [9]. Recently, an European consortium with 30 partners from 9 European countries under the direction of Infineon has developed a spoke rotor PMSM that uses ferrite magnets with a similar or better power density than an equivalent induction motor [50,78]. The Department of Energy of the United States is financing a similar project called FreedomCar to develop a spoke rotor PMSM with ferrite magnets [79].

\subsection{Switched reluctance machines (SRMs)}

SRMs are brushless machines [80] that present a doubly salient structure since both rotor and stator have salient-pole structure. The stator has wound field windings similar to the stator windings of DC motors. The rotor has neither windings nor PMs. The rotor tends to shift towards the position of the excited stator winding, in order to maximize the inductance (minimize the reluctance) [81], thus aligning the rotor pole with the closest stator pole. To maintain the rotor in motion, it is required to excite the stator poles in a sequence, which is done by an electronic controller. Conventional inner rotor SRMs have radial flux and doubly saliency, as shown in Fig. 6, although axial flux and outer rotor topologies exist.

\section{HERE FIGURE 6}

SRMs can have different phases number, being most frequent 3 or 4 phases. SRMs are usually fed by shifted pulsed DC phase voltages, whereas the phase currents have a near trapezoidal shape. To generate sufficient reluctance torque, SRMs must work under deep saturation conditions; therefore the air gap is usually very small and the magnetic properties of the stator and rotor steel laminations are especially important [81]. Since the power flows through the narrow air gap in the radial direction, important radial forces, vibrations and acoustic noise are generated [9,82]. SRMs present inherent fault tolerant capability since they have concentrated phase windings which are independent and isolated from each other. Therefore, when a phase fails, the SRM may still operate at reduced power with the remaining healthy phases [44].

SRMs are simple and inexpensive machines because of their simple construction, easy assembly and therefore easy manufacturing [6,57,80], in part due to the absence of windings and PMs in the rotor [44], and offer an extended CPSR up to 7 [46], these being very appealing features for gearless EV drives. Since SRMs are PM-free machines, they allow high temperature operation $[69,82]$. SRMs also exhibit low rotor inertia and high start-up torque and therefore fast acceleration capability [3]. SRMs have concentrated windings which have good thermal performance and therefore inherent fault tolerant capability. In addition, SRMs are easily cooled since the heat generated by both iron and copper loss is mainly concentrated in the stator [44]. Test results also prove higher power density than IMs [46]. However, SRMs present inherent limitations, including high torque ripple, high vibrations and acoustic noise levels and complex control due to the high nonlinear behavior or higher iron losses compared to IPMSMs because the higher frequency of the flux, thus presenting lower efficiency [57].

According to [83], to improve torque density and efficiency and the operating area, the number of stator and rotor pols must be increased, extremely low-loss laminations must be used and the continuous current mode of operation must be applied at high speeds.

Some authors are considering the possibility of adding permanent magnets within the stator structure to further increase the torque density and efficiency while minimizing torque ripple $[84,85]$. However these 
motor types are still under research and are not considered in this paper.

To the authors' knowledge there are still no commercially available FEVs incorporating SRMs although several manufacturers including Rocky Mountain Technologies [86] or US Motors [87] among others commercialize SRMs for industrial applications in the range $0.4-160 \mathrm{~kW}$.

\subsection{Flux switching machines (FSMs)}

Flux switching motors (FSMs) are double salient brushless machines that are being studied for traction applications [88]. The stator contains both the DC field winding and the armature windings, the latter ones being usually fed by sinusoidal three-phase voltages/currents $[89,90]$ thus reducing vibrations and acoustic noise compared to SRMs. The DC field winding, which establishes the stator flux, can be replaced by PMs. FSMs require supplying both windings continuously throughout the motor operation. By reversing the current polarity in the armature windings, the direction of the magnetic flux in the stator is switched from a pair of stator poles to a quadrature pair of stator poles, thus controlling the stator poles to which the rotor is attracted. As the rotor contains neither windings nor PMs, it presents a simple and strong structure, thus being suitable for high speed operation [88]. Although inner rotor FSMs are more common, they also can be constructed with outer rotor geometry $[88,91]$ for in-wheel applications.

FSMs can be classified into wounded field FSMs (WFFSMs), permanent magnet FSMs (PMFSMs) and hybrid excitation FSMs (HEFSM), the latter ones combining both field excitation coils and PMs as main flux sources [92]. Different linear FSM topologies have been developed [93], some of them include hybrid excitation, that is, combine three-phase windings and PMs [94,95]. PMFSMs are also being developed using ferrite PMs [96]. However, PMFSMs exhibit limited CPSR due to poor field weakening capabilities. The CPSR can be greatly extended by replacing the PMs by DC field windings, that is, by using WFFSMs [97]. Therefore WFFSMs are well-suited for EVs propulsion systems.

Appealing features of FSMs include simple construction and easy manufacture, robustness since the rotor is a single piece of magnetic steel laminations [98] with neither PMs nor windings, high air gap flux density and therefore high power and torque densities [97,99,100]. Therefore FSMs can be used in harsh environments. However FSMs exhibit higher copper losses and an inherent large torque ripple, due to the reluctance torque and especially due to the cogging torque which is the main component of the torque [99]. This effect also generates vibrations and acoustic noise, which are especially notorious at low speed operation [101]. Fig. 7 shows the cross-sections of a WFFSM and a PMFSM.

\section{HERE FIGURE 7}

Some manufacturers such as Technelec Ltd. [102] offer FSMs for industrial applications. However, to the authors' knowledge there are still no commercially available FEVs driven by FSMs although there are initiatives to develop FSMs for EV applications [103].

\subsection{Synchronous reluctance motor (SynRM)}

As the name indicates, SynRMs are synchronous machines usually supplied by three-phase AC voltages. The ducted rotor of a SynRM is made of magnetic steel laminations with neither current-conducting paths nor windings or PMs. Therefore rotor losses are very low. The only component of the torque in a SynRM is the reluctance torque [104], therefore SynRMs must present a very high salience ratio $L_{d} / L_{q}$ to increase the efficiency, maximum torque, power factor and constant-power speed range (CPSR) [70]. To this end a multi flux barrier structure is applied in the rotor [9], with the flux barriers perpendicular to the flux lines. The flux barriers guide the flux through the desired paths, that is, whereas the q-axis flux is blocked by the flux barriers, the d-axis flux is guided through an iron path [105]. This design strategy, jointly with the use of axially-laminated (ALA) rotors, allows obtaining a reasonably small $L_{q}$ inductance due to the large air gap path [104]. The salience ratio can be increased by appropriate placement, number and geometry of flux barriers, a challenging design task. The rotor has low inertia because of the air flux barriers [106]. Since the 
rotor is only made of magnetic steel laminations and the stator is very similar to that of a conventional induction motor, SynRMs are easy to manufacture [88]. However, SynRMs have lower efficiency, torque density and power factor than PMSMs [72] although SynRMs are competitive with induction machines in terms of power factor, inverter kVA requirements, and easy speed control without encoders even at low or zero speed operation [104]. SynRMs are usually controlled by either vector or direct torque control.

Main weaknesses of SynRMs are high torque ripple [107] and low torque density which can be partially overcome by an adequate design of the magnetic configuration of the rotor [88]. Appropriate selection of the number of flux barriers taking care of their geometry [107] and rotor skewing by one stator slot pitch allows drastically dropping the torque ripple while reducing slightly the average torque [104].

Different motor manufacturers such as Kaiser Motoren [108], ABB [109] or REEL [110] commercialize magnet-free SynRMs for industrial applications in the range 0.55 to $315 \mathrm{~kW}$. Recently Ricardo [111] has announced the development of a $85 \mathrm{~kW}$ SynRM prototype intended for electric vehicles.

\subsection{Ferrite-PM-Assisted synchronous reluctance motor (PMa-SynRM)}

According to [88], the cost of rare-earth PMs can be about $60 \%$ the total costs of materials of an IPMSM machine. Therefore, by replacing the rare-earth PMs by ferrite magnets the material costs can be reduced by $50 \%$.

Torque density and torque production capability in SynRMs can be increased by incorporating magnets in the rotor [112,113], thus resulting a PMa-SynRM, which is a promising candidate to propel EVs. This motor is similar to an IPMSM. The ferrite magnets are inserted in the rotor flux barriers on the quadrature axis to increase the saliency ratio [9]. PMs' polarity is selected to counteract the magnetic flux in the q-axis to minimize $L_{q}$, thus maximizing the $L_{d} / L_{q}$ saliency ratio [114,115], so PMa-SynRMs increase the reluctance torque, which is much greater than the alignment torque [71]. Due to the cost and supply risk issues associated to rare-earth PMs, PMa-SynRMs based on cost effective ferrite PMs are being developed. PMa-SynRMs combine the features of PM and reluctance machines, thus presenting high efficiency, high density, high power factor and a wide speed range.

The air flux barriers partially protect the PMs against demagnetization [114,116] although there is a risk of demagnetization when operating at extremely low temperatures [117].

PMa-SynRMs use lower PMs mass than IPMSMs [107], thus inducing lower back-EMF and lower shortcircuit currents [106]. In addition they use ferrite instead of NdFeB PMs and the flux-linkages due to PMs are smaller compared to those of conventional IPMSMs [114]. In IPMSMs the main component of the flux comes from the PMs, so the repulsion torque is the main torque component, however PMa-SynRMs maximize the reluctance torque [115].

A conventional three phase inverter can be used to drive the motor PMa-SynRM [115]. PMa-SynRMs are often most saturated than SynRMs because the supplementary flux of the PMs [118].

The structure of PMa-SynRMs is very similar to that of IPMSMs, but the rotor is designed to raise the magnetic saliency in order to further increase the reluctance torque, thus enhancing flux weakening performance at high speed operation and increasing the power density [71,119] and the overload capability [107]. To maximize the magnetic saliency and thus the reluctance torque, the rotor has a multi-layered cavity structure with buried ferrite PMs, as displayed in Fig. 8.

\section{HERE FIGURE 8}

To the authors' knowledge there are still no commercially available FEVs incorporating PMa-SynRMs although motor manufacturers such as Kaiser Motoren [108] commercialize rare-earth PMa-SynRMs for industrial applications. The authors of this work are also developing a $60 \mathrm{~kW}$ ferrite PMa-SynRM prototype for electric vehicle applications.

\subsection{Comparison of different motors without rare-earth PMs}

Fig. 9 compares the maximum efficiency and torque density of the different motors types analyzed in this 
paper based on data found in the bibliography. The rare-earth based IPMSM of the third-generation HEV Toyota Prius has also been included since it is often taken as a reference machine.

\section{HERE FIGURE 9}

Another interesting performance index which allows comparing different machines is the machine constant of mechanical power $[131,132]$,

$$
C_{\text {mec }}=\frac{P_{\text {mec }}}{D^{2} \cdot l_{\text {eff }} \cdot n_{\text {rated }}}
$$

$P_{\text {mec }}$ being the mechanical power in $\mathrm{kW}, D$ the bore diameter in $\mathrm{m}, l_{\text {eff }}$ the effective length of the stator stack in $\mathrm{m}\left(l_{\text {eff }}=l+2 \cdot g\right.$, where $l$ is the stack length and $g$ the air gap) and $n_{\text {rated }}$ the rated frequency of the rotor in $\mathrm{s}^{-1}$. As deduced from (1), the machine constant of mechanical power, expressed in $\mathrm{kW} \cdot \mathrm{s} / \mathrm{m}^{3}$, takes into account the output rotor power per unit active volume and per unit speed since it is normalized with respect to $D^{2} \cdot l_{\text {eff }}$ and $n_{\text {rated }}$, respectively. The machine constant of mechanical power can be interpreted as a mechanical utilization factor of the analyzed machine and allows comparing the performance of different machines in a different way than it does the torque density.

Fig. 10 compares the machine constant of mechanical power and the maximum efficiency of the different motors types analyzed in this paper based on data found in the technical bibliography.

\section{HERE FIGURE 10}

It is worth pointing out that the data presented in Figs. 9 and 10 have been obtained from different motor types and configurations with different power and speed ranges and different current densities and cooling systems. In addition, some of these motors are manufactured prototypes whereas others are based on finite element method simulations, thus the results must be carefully interpreted. As illustrated in Figs. 9 and 10, among the analyzed motor types, that is, SRM, WFFSM, PMFSM, PMaSynRM, PMSM and SCIM there is not a clear candidate. Other factors such as torque ripple, audible noise and vibrations, ease of manufacture, robustness, fault tolerant capability, CPSR region or facility of control among others must be taken into account to select a determined machine. Therefore, it has to be deeply analyzed which motor type is the one that better fulfills the constraints and target values of the specific application dealt with.

\section{CONCLUSION}

Although many of the current electric motors for HEVs and FEVs are using rare-earth PMs, there are different possibilities to develop rare-earth-free electric motors for such applications. This work has done a deep literature review in this field, which is generating a growing interest due to the cost and supply risks concerns related to rare-earth PMs. The results presented show that some of the rare-earth-free motors reviewed can achieve similar performance in terms of torque density, efficiency or machine constant of mechanical power as compared to the state-of-the-art rare-earth based electric motors. In addition some of them have other interesting features including lower cost, better ruggedness, higher temperature operation, impossibility of being demagnetized, wider CPSR or improved efficiency, this last being a very appealing feature to extend the vehicle range. Due to the higher complexity and number of components in HEVs and PHEVs, they require more compacted motors than FEVs. As a result, when dealing with a particular application, it has to be analyzed in detail to find out which motor type can satisfy the target values. Therefore, when considering other aspects like efficiency, material costs and supply risk among others, rare-earth-free motors can be competitive with respect to the reference rare-earth based motors. 


\section{ACKNOWLEDGEMENTS}

This work was supported in part by the Spanish Ministry of Science and Technology under the TRA201346757-R research Project, and by the Catalan Agència de Gestió d'Ajuts Universitaris i de Recerca, under the AGAUR 2014 SGR-101 Research Project.

\section{REFERENCES}

[1] Hoenderdaal S, Tercero Espinoza L, Marscheider-Weidemann F, Graus W. Can a dysprosium shortage threaten green energy technologies? Energy 2013;49:344-55.

doi:10.1016/j.energy.2012.10.043.

[2] Habib K, Wenzel H. Exploring rare earths supply constraints for the emerging clean energy technologies and the role of recycling. J Clean Prod 2014;84:348-59.

doi:10.1016/j.jclepro.2014.04.035.

[3] Amjad S, Neelakrishnan S, Rudramoorthy R. Review of design considerations and technological challenges for successful development and deployment of plug-in hybrid electric vehicles. Renew Sustain Energy Rev 2010;14:1104-10.

[4] Poullikkas A. Sustainable options for electric vehicle technologies. Renew Sustain Energy Rev 2015;41:1277-87. doi:10.1016/j.rser.2014.09.016.

[5] Collocott SJ, Dunlop JB, Gwan PB, Kalan B a., Lovatt HC, Wu W, et al. Applications of rare-earth permanent magnets in electrical machines: from motors for niche applications to hybrid electric vehicles. In: Assoc. CMM and D, editor. 2004 China Magn. Symp., vol. 315, Xi'an: China Magnetic Materials and Devices Assoc.; 1999, p. 77-83.

[6] Kumar L, Jain S. Electric propulsion system for electric vehicular technology: A review. Renew Sustain Energy Rev 2014;29:924-40. doi:10.1016/j.rser.2013.09.014.

[7] Hannan M a., Azidin F a., Mohamed a. Hybrid electric vehicles and their challenges: A review. Renew Sustain Energy Rev 2014;29:135-50. doi:10.1016/j.rser.2013.08.097.

[8] Tie SF, Tan CW. A review of energy sources and energy management system in electric vehicles. Renew Sustain Energy Rev 2013;20:82-102. doi:10.1016/j.rser.2012.11.077.

[9] Boldea I, Tutelea LN, Parsa L, Dorrell D. Automotive electric propulsion systems with reduced or no permanent magnets: An overview. IEEE Trans Ind Electron 2014;61:5696-711.

doi:10.1109/TIE.2014.2301754.

[10] Dallinger D, Wietschel M. Grid integration of intermittent renewable energy sources using priceresponsive plug-in electric vehicles. Renew Sustain Energy Rev 2012;16:3370-82. doi:10.1016/j.rser.2012.02.019.

[11] Richardson DB. Electric vehicles and the electric grid: A review of modeling approaches, Impacts, and renewable energy integration. Renew Sustain Energy Rev 2013;19:247-54. doi:10.1016/j.rser.2012.11.042.

[12] Urresty JC, Riba JR, Delgado M, Romeral L. Detection of demagnetization faults in surfacemounted permanent magnet synchronous motors by means of the zero-sequence voltage component. IEEE Trans Energy Convers 2012;27:42-51. doi:10.1109/TEC.2011.2176127.

[13] Ramsden VS, Watterson P a., Hunter GP, Zhu JG, Holliday WM, Lovatt HC, et al. Highperformance electric machines for renewable energy generation and efficient drives. Renew Energy 2001;22:159-67. doi:10.1016/S0960-1481(00)00054-9. 
[14] Bai G, Gao RW, Sun Y, Han GB, Wang B. Study of high-coercivity sintered NdFeB magnets. J Magn Magn Mater 2007;308:20-3. doi:10.1016/j.jmmm.2006.04.029.

[15] Romeral L, Urresty JC, Riba Ruiz JR, Garcia Espinosa A. Modeling of surface-mounted permanent magnet synchronous motors with stator winding interturn faults. IEEE Trans Ind Electron 2011;58:1576-85. doi:10.1109/TIE.2010.2062480.

[16] Saavedra H, Urresty J-C, Riba J-R, Romeral L. Detection of interturn faults in PMSMs with different winding configurations. Energy Convers Manag 2014;79:534-42. doi:10.1016/j.enconman.2013.12.059.

[17] Urresty JC, Riba JR, Romeral L. A back-emf based method to detect magnet failures in PMSMs. IEEE Trans Magn 2013;49:591-8. doi:10.1109/TMAG.2012.2207731.

[18] Lacal-Arántegui R. Materials use in electricity generators in wind turbines - state-of-the-art and future specifications. J Clean Prod 2015;87:275-83. doi:10.1016/j.jclepro.2014.09.047.

[19] Elshkaki A, Graedel TE. Dysprosium, the balance problem, and wind power technology. Appl Energy 2014;136:548-59. doi:10.1016/j.apenergy.2014.09.064.

[20] Smith Stegen K. Heavy rare earths, permanent magnets, and renewable energies: An imminent crisis. Energy Policy 2015;79:1-8. doi:10.1016/j.enpol.2014.12.015.

[21] Dent PC. High performance magnet materials: risk supply chain. Adv Mater Process 2009:27-30.

[22] Binnemans K, Jones PT, Blanpain B, Van Gerven T, Yang Y, Walton A, et al. Recycling of rare earths: A critical review. J Clean Prod 2013;51:1-22. doi:10.1016/j.jclepro.2012.12.037.

[23] Machacek E, Fold N. Alternative value chains for rare earths: The Anglo-deposit developers. Resour Policy 2014;42:53-64. doi:10.1016/j.resourpol.2014.09.003.

[24] Information Office of the State Council. The People's Republic of China. Situation and Policies of China's Rare Earth Industry. 2010. http://english.gov.cn/archive/white_paper/2014/08/23/content_281474983043156.htm (accessed March 10, 2015).

[25] Ly V, Wu X, Smillie L, Shoji T, Kato a., Manabe a., et al. Low-temperature phase MnBi compound: A potential candidate for rare-earth free permanent magnets. J Alloys Compd 2014;615:285-90. doi:10.1016/j.jallcom.2014.01.120.

[26] Critical raw materials for the EU: Report of the Ad-hoc Working Group on defining critical raw materials - European Commission n.d. http://ec.europa.eu/eip/rawmaterials/en/community/document/critical-raw-materials-eu-report-ad-hoc-working-group-definingcritical-raw (accessed March 10, 2015).

[27] 2011 Critical Materials Strategy. U.S. Department of Energy 2011:1-191. doi:DOE/PI-0009.

[28] Massari S, Ruberti M. Rare earth elements as critical raw materials: Focus on international markets and future strategies. Resour Policy 2013;38:36-43. doi:10.1016/j.resourpol.2012.07.001.

[29] Goto R, Matsuura M, Sugimoto S, Tezuka N, Une Y, Sagawa M. Microstructure evaluation for Dyfree Nd-Fe-B sintered magnets with high coercivity. J Appl Phys 2012;111:07A739. doi:10.1063/1.3680190.

[30] Fastenau RHJ, Van Loenen EJ. Applications of rare earth permanent magnets. J Magn Magn Mater 1996;157-158:1-6. doi:10.1016/0304-8853(95)01279-6.

[31] Highly efficient industrial $11 \mathrm{~kW}$ permanent magnet synchronous motor without rare-earth metals 
n.d. http://www.hitachi.com/New/cnews/120411.html (accessed March 10, 2015).

[32] Wübbeke J. Rare earth elements in China: Policies and narratives of reinventing an industry. Resour Policy 2013;38:1-11. doi:10.1016/j.resourpol.2013.05.005.

[33] Kanazawa Y, Kamitani M. Rare earth minerals and resources in the world. J Alloys Compd 2006;408-412:1339-43. doi:10.1016/j.jallcom.2005.04.033.

[34] Christmann P. A Forward Look into Rare Earth Supply and Demand: A Role for Sedimentary Phosphate Deposits? Procedia Eng 2014;83:19-26. doi:10.1016/j.proeng.2014.09.005.

[35] Encinas-ferrer C, Valderrey-villar FJ, Hernandez-rodriguez C, Uson-sardaña A. The World Production and Trade of Rare Earth Elements: The Position of the Pacific Area * 2014;13:209-20.

[36] Peng L, Yang Q, Zhang H, Xu G, Zhang M, Wang J. Rare earth permanent magnets Sm2(Co, Fe, $\mathrm{Cu}, \mathrm{Zr}) 17$ for high temperature applications. J Rare Earths 2008;26:378-82. doi:10.1016/S10020721(08)60100-3.

[37] Coey JMD. Permanent magnets: Plugging the gap. Scr Mater 2012;67:524-9. doi:10.1016/j.scriptamat.2012.04.036.

[38] Lewis LH, Jiménez-Villacorta F. Perspectives on Permanent Magnetic Materials for Energy Conversion and Power Generation. Metall Mater Trans A 2012;44:2-20. doi:10.1007/s11661-0121278-2.

[39] Magnetic Materials Producers Association. MMPA Standard 0100-00. Standard Specifications for Permanent Magnet Materials n.d. http://www.intemag.com/pdf/MMPA0100-00.pdf (accessed November 22, 2015).

[40] Rare Earth Elements: The Global Supply Chain n.d. http://www.scor.com/en/sgrc/pac/motor/item/1513-rare-earth-elements-the-global-supplychain/1513-rare-earth-elements-the-global-supply-chain.html (accessed March 10, 2015).

[41] Wellington T a, Mason TE. The effects of population growth and advancements in technology on global mineral supply. Resour Policy 2014;42:73-82. doi:10.1016/j.resourpol.2014.10.006.

[42] Grosjean C, Herrera Miranda P, Perrin M, Poggi P. Assessment of world lithium resources and consequences of their geographic distribution on the expected development of the electric vehicle industry. Renew Sustain Energy Rev 2012;16:1735-44. doi:10.1016/j.rser.2011.11.023.

[43] Bradley TH, Frank A a. Design, demonstrations and sustainability impact assessments for plug-in hybrid electric vehicles. Renew Sustain Energy Rev 2009;13:115-28. doi:10.1016/j.rser.2007.05.003.

[44] Xue XD, Cheng K, Cheung NC. Selection of electric motor drives for electric vehicles. 2008 Australas Univ Power Eng Conf 2008:1-6.

[45] Lazari P, Wang J, Chen L, Chen X. Design optimisation and performance evaluation of a rare-earthfree Permanent Magnet Assisted Synchronous Reluctance Machine for electric vehicle traction. Power Electron. Mach. Drives (PEMD 2014), 7th IET Int. Conf., Institution of Engineering and Technology; 2014, p. 1-6. doi:10.1049/cp.2014.0453.

[46] Moore S, Rahman K, Ehsani M. Effect on vehicle performance of extending the constant power region of electric drive motors. 1999. doi:10.4271/1999-01-1152.

[47] Lundmark ST, Alatalo M. A segmented claw-pole motor for traction applications considering recycling aspects. 2013 Eighth Int. Conf. Exhib. Ecol. Veh. Renew. Energies, IEEE; 2013, p. 1-6. 
doi:10.1109/EVER.2013.6521613.

[48] de Santiago J, Bernhoff H, Ekergård B, Eriksson S, Ferhatovic S, Waters R, et al. Electrical Motor Drivelines in Commercial All-Electric Vehicles: A Review. IEEE Trans Veh Technol 2012;61:47584. doi:10.1109/TVT.2011.2177873.

[49] Vignaud A, Fennel H. Efficient electric powertrain with externally excited synchronous machines without rare earth magnets using the example of the Renault System Solution. Vienna Mot Symp n.d.:1-8. http://myrenaultzoe.com/Docs/2012_wien_vortrag_uv.pdf (accessed November 28, 2015).

[50] Widmer JD, Martin R, Kimiabeigi M. Electric vehicle traction motors without rare earth magnets. Sustain Mater Technol 2015;3:7-13. doi:10.1016/j.susmat.2015.02.001.

[51] Haubert T. Optimal Control of Mathematical Model of the Electrovehicle. Czech Technical University in Prague, 2015.

[52] Zeraoulia M, Benbouzid MEH, Diallo D. Electric Motor Drive Selection Issues for HEV Propulsion Systems: A Comparative Study. IEEE Trans Veh Technol 2006;55:1756-64.

doi:10.1109/TVT.2006.878719.

[53] Urresty JC, Riba JR, Romeral L. Diagnosis of interturn faults in pmsms operating under nonstationary conditions by applying order tracking filtering. IEEE Trans Power Electron 2013;28:507-15. doi:10.1109/TPEL.2012.2198077.

[54] Ruiz JRR, Garcia Espinosa A, Romeral L, Cusidó J. Demagnetization diagnosis in permanent magnet synchronous motors under non-stationary speed conditions. Electr Power Syst Res 2010;80:1277-85. doi:10.1016/j.epsr.2010.04.010.

[55] Akatsu K, Matsui N. New trend of motor technology for automobiles - Introduction and overview. 2013 IEEE ECCE Asia Downunder, IEEE; 2013, p. 130-5. doi:10.1109/ECCE-Asia.2013.6579085.

[56] Fasquelle a., Le Besnerais J, Harmand S, Hecquet M, Brisset S, Brochet P, et al. Coupled electromagnetic acoustic and thermal-flow modeling of an induction motor of railway traction. Appl Therm Eng 2010;30:2788-95. doi:10.1016/j.applthermaleng.2010.08.007.

[57] Dorrell DG, Knight a. M, Popescu M, Evans L, Staton D a. Comparison of different motor design drives for hybrid electric vehicles. Energy Convers. Congr. Expo. (ECCE), 2010 IEEE, IEEE; 2010, p. 3352-9. doi:10.1109/ECCE.2010.5618318.

[58] Singh G. Multi-phase induction machine drive research - a survey. Electr Power Syst Res 2002;61:139-47. doi:10.1016/S0378-7796(02)00007-X.

[59] Boglietti A, Cavagnino A, Feraris L, Lazzari M. Energy-efficient motors. IEEE Ind Electron Mag 2008;2:32-7. doi:10.1109/MIE.2008.930360.

[60] Kirtley JL, Cowie JG, Brush EF, Peters DT, Kimmich R. Improving induction motor efficiency with die-cast copper rotor cages. 2007 IEEE Power Eng. Soc. Gen. Meet. PES, IEEE; 2007, p. 1-6. doi:10.1109/PES.2007.385767.

[61] Hyun Rok Cha, Tae Won Jeong, Dae Yeong Im, Kyoo Jae Shin, Young Ju Seo, Components A, et al. Design of outer rotor type induction motor having high power density for in-wheel system 2012:1-4.

[62] Petrov I, Pyrhonen J. Performance of low-cost permanent magnet material in PM synchronous machines. IEEE Trans Ind Electron 2013;60:2131-8. doi:10.1109/TIE.2012.2191757.

[63] Pillay P, Krishnan R. Application characteristics of permanent magnet synchronous and brushless 
DC motors for servo drives. IEEE Trans Ind Appl 1991;27:986-96. doi:10.1109/28.90357.

[64] Kato T, Limsuwan N, Yu CY, Akatsu K, Lorenz RD. Rare earth reduction using a novel variable magnetomotive force flux-intensified IPM machine. IEEE Trans. Ind. Appl., vol. 50, IEEE; 2014, p. 1748-56. doi:10.1109/TIA.2013.2283314.

[65] Chung S-U, Kim J-W, Chun Y-D, Woo B-C, Hong D-K. Fractional Slot Concentrated Winding PMSM With Consequent Pole Rotor for a Low-Speed Direct Drive: Reduction of Rare Earth Permanent Magnet. IEEE Trans Energy Convers 2015;30:103-9. doi:10.1109/TEC.2014.2352365.

[66] Sergeant P, Van Den Bossche APM. Influence of the amount of permanent-magnet material in fractional-slot permanent-magnet synchronous machines. IEEE Trans Ind Electron 2014;61:497989. doi:10.1109/TIE.2013.2258310.

[67] Urresty J-C, Riba J-R, Romeral L, Ortega JA. Mixed resistive unbalance and winding inter-turn faults model of permanent magnet synchronous motors. Electr Eng 2014;97:75-85. doi:10.1007/s00202-014-0316-z.

[68] Montalvo-Ortiz EE, Foster SN, Cintron-Rivera JG, Strangas EG. Comparison between a spoke-type PMSM and a PMASynRM using ferrite magnets. 2013 Int. Electr. Mach. Drives Conf., IEEE; 2013, p. 1080-7. doi:10.1109/IEMDC.2013.6556230.

[69] Chiba A, Takeno M, Hoshi N, Takemoto M, Ogasawara S, Rahman MA. Consideration of number of series turns in switched-reluctance traction motor competitive to HEV IPMSM. IEEE Trans Ind Appl 2012;48:2333-40. doi:10.1109/TIA.2012.2227093.

[70] Guglielmi P, Boazzo B, Armando E, Pellegrino G, Vagati A. Permanent-magnet minimization in PM-assisted synchronous reluctance motors for wide speed range. IEEE Trans Ind Appl 2013;49:3141. doi:10.1109/TIA.2012.2229372.

[71] Jeong Y-H, Kim K, Kim Y-J, Park B-S, Jung S-Y. Design characteristics of PMa-SynRM and performance comparison with IPMSM based on numerical analysis. 2012 XXth Int. Conf. Electr. Mach., IEEE; 2012, p. 164-70. doi:10.1109/ICElMach.2012.6349858.

[72] Morimoto S, Ooi S, Inoue Y, Sanada M. Experimental evaluation of a rare-earth-free PMASynRM with ferrite magnets for automotive applications. IEEE Trans Ind Electron 2014;61:5749-56. doi:10.1109/TIE.2013.2289856.

[73] Zhao W, Lipo T a., Kwon B-I. Comparative Study on Novel Dual Stator Radial Flux and Axial Flux Permanent Magnet Motors With Ferrite Magnets for Traction Application. IEEE Trans Magn 2014;50:1-4. doi:10.1109/TMAG.2014.2329506.

[74] Chiba K, Chino S, Takemoto M, Ogasawara S. Fundamental analysis for a ferrite permanent magnet axial gap motor with coreless rotor structure. 15th Int. Conf. Electr. Mach. Syst. (ICEMS), 2012, IEEE; 2012, p. 1-6.

[75] Matsuhashi D, Matsuo K, Okitsu T, Ashikaga T, Mizuno T. Comparison study of various motors for EVs and the potentiality of a ferrite magnet motor. 2014 Int. Power Electron. Conf. (IPECHiroshima 2014 - ECCE ASIA), IEEE; 2014, p. 1886-91. doi:10.1109/IPEC.2014.6869842.

[76] Sone K, Takemoto M, Ogasawara S, Takezaki K, Akiyama H. A ferrite PM in-wheel motor without rare earth materials for electric city commuters. IEEE Trans Magn 2012;48:2961-4. doi:10.1109/TMAG.2012.2196685.

[77] Miura T, Chino S, Takemoto M, Ogasawara S, Akira Chiba, Nobukazu Hoshi. A ferrite permanent magnet axial gap motor with segmented rotor structure for the next generation hybrid vehicle. XIX 
Int. Conf. Electr. Mach. - ICEM 2010, IEEE; 2010, p. 1-6. doi:10.1109/ICELMACH.2010.5607864.

[78] Morris C. MotorBrain to debut integrated EV drivetrain with no rare earth metals. Electr Veh Mag 2015:1.

[79] Galioto SJ, Reddy PB, EL-Refaie AM, Alexander JP. Effect of Magnet Types on Performance of High-Speed Spoke Interior-Permanent-Magnet Machines Designed for Traction Applications. IEEE Trans Ind Appl 2015;51:2148-60. doi:10.1109/TIA.2014.2375380.

[80] Kim J, Jeong Y, Jeon Y-H, Kang J-H, Lee S, Park J-Y. Development of a Switched Reluctance Motor-based Electric AC Compressor Drive for HEV/EV Applications. J Magn 2014;19:282-90.

[81] Riba J-R, Garcia a., Romeral L. A computer experiment to simulate the dynamic behaviour of electric vehicles driven by switched reluctance motors. Int J Electr Eng Educ 2014;51:368-82. doi:10.7227/IJEEE.0008.

[82] Ishikawa T, Dohmeki H. The fundamental design technique of switched reluctance motors, and comparison with PMSM. Proc. - 2012 20th Int. Conf. Electr. Mach. ICEM 2012, IEEE; 2012, p. 500-4. doi:10.1109/ICElMach.2012.6349916.

[83] Chiba A, Kiyota K, Hoshi N, Takemoto M, Ogasawara S. Development of a Rare-Earth-Free SR Motor With High Torque Density for Hybrid Vehicles. IEEE Trans Energy Convers 2015;30:17582. doi:10.1109/TEC.2014.2343962.

[84] Hwang H, Hur J, Lee C. Novel permanent-magnet-assisted switched reluctance motor (I): Concept, design, and analysis. 2013 Int. Conf. Electr. Mach. Syst., IEEE; 2013, p. 602-8.

doi:10.1109/ICEMS.2013.6754501.

[85] Zhang J, Lu X, Lu J, Kang Q, Dong X. Study of the New Permanent Magnet switched reluctance motor. 2011 Int. Conf. Adv. Power Syst. Autom. Prot., vol. 3, IEEE; 2011, p. 1684-7. doi:10.1109/APAP.2011.6180757.

[86] Rocky Mountain Technologies 2015. http://www.rockymountaintechnologies.com/SR_Motors.html (accessed November 29, 2015).

[87] U.S. Motors. Switched Reluctance - Range Overview \& Datasheets n.d. http://www.usmotors.com/Our-Products/Switched-Reluctance/RangeOverview-Datasheets.aspx (accessed November 29, 2015).

[88] Cai H, Guan B, Xu L. Low-cost ferrite PM-assisted synchronous reluctance machine for electric vehicles. IEEE Trans Ind Electron 2014;61:5741-8. doi:10.1109/TIE.2014.2304702.

[89] Zulu A. Flux switching machines using segmental rotors. Newcastle University. School of Electrical, Electronic and Computer Engineering 2010. https://theses.ncl.ac.uk/dspace/handle/10443/1070 (accessed March 10, 2015).

[90] Sulaiman E Bin, Kosaka T, Matsui N. Design study and experimental analysis of wound field flux switching motor for HEV applications. Proc. - 2012 20th Int. Conf. Electr. Mach. ICEM 2012, IEEE; 2012, p. 1269-75. doi:10.1109/ICElMach.2012.6350039.

[91] Xiang Z, Quan L, Zong Z, Gu Y, Yin J. Alternative stator for new brushless dual-rotor fluxswitching permanent magnet motor for extended range electric vehicles. 2014 17th Int. Conf. Electr. Mach. Syst., IEEE; 2014, p. 212-7. doi:10.1109/ICEMS.2014.7013484.

[92] Husin ZA, Sulaiman E, Kosaka T. Design studies and effect of various rotor pole number of field excitation flux switching motor for hybrid electric vehicle applications. 2014 IEEE 8th Int. Power Eng. Optim. Conf., IEEE; 2014, p. 144-9. doi:10.1109/PEOCO.2014.6814415. 
[93] Tan Q, Huang X, Zhou B, Wang Q. Analysis and optimization of the inner armature tubular fluxswitching permanent magnet linear motor. 2014 17th Int. Conf. Electr. Mach. Syst., IEEE; 2014, p. 1263-7. doi:10.1109/ICEMS.2014.7013680.

[94] Cai J, Lu Q, Jin Y, Chen C, Ye Y. Performance investigation of multi-tooth flux-switching PM linear motor. 2011 Int. Conf. Electr. Mach. Syst. ICEMS 2011, IEEE; 2011, p. 1-6. doi:10.1109/ICEMS.2011.6073745.

[95] Hwang CC, Li PL, Liu CT. Design and analysis of a novel hybrid excited linear flux switching permanent magnet motor. IEEE Trans Magn 2012;48:2969-72. doi:10.1109/TMAG.2012.2195716.

[96] Yin J, Quan L, Zhu X, Xiang Z, Zhou H. The performance of a hybrid excitation flux switching motor with ferrite magnets for EVs. 2014 IEEE Conf. Expo Transp. Electrif. Asia-Pacific (ITEC Asia-Pacific), IEEE; 2014, p. 1-4. doi:10.1109/ITEC-AP.2014.6941227.

[97] Tang Y, Paulides JJH, Lomonova E a. Automated design of DC-excited flux-switching in-wheel motor using magnetic equivalent circuits. 2014 9th Int. Conf. Ecol. Veh. Renew. Energies, EVER 2014, IEEE; 2014, p. 1-10. doi:10.1109/EVER.2014.6844005.

[98] Sulaiman E, Khan F, Ahmad MZ, Jenal M, Zulkifli SA, Bakar AA. Investigation of field excitation switched flux motor with segmental rotor. 2013 IEEE Conf. Clean Energy Technol., IEEE; 2013, p. 317-22. doi:10.1109/CEAT.2013.6775648.

[99] Wei Hua, Ming Cheng, Gan Zhang. A Novel Hybrid Excitation Flux-Switching Motor for Hybrid Vehicles. IEEE Trans Magn 2009;45:4728-31. doi:10.1109/TMAG.2009.2022497.

[100] Somesan L, Padurariu E, Viorel I-A, Szabo L. Design of a permanent magnet flux-switching machine. 2012 ELEKTRO, IEEE; 2012, p. 256-9. doi:10.1109/ELEKTRO.2012.6225649.

[101] Jia H, Cheng M, Hua W, Zhao W, Li W. Torque Ripple Suppression in Flux-Switching PM Motor by Harmonic Current Injection Based on Voltage Space-Vector Modulation. IEEE Trans Magn 2010;46:1527-30. doi:10.1109/TMAG.2010.2040250.

[102] Technelec Ltd. Flux switching motors. n.d. http://www.technelec.co.uk/About Us/About.html (accessed November 29, 2015).

[103] Kosaka T, Matsui N, Kamada Y, Kajiura H. Experimental Drive Performance Evaluation of High Power Density Wound Field Flux Switching Motor for Automotive Applications. 7th IET Int. Conf. Power Electron. Mach. Drives (PEMD 2014), Institution of Engineering and Technology; 2014, p. 1-6. doi:10.1049/cp.2014.0461.

[104] Haataja J. A comparative performance study of four-pole induction motors and synchronous reluctance motors in variable speed drives. Lappeenranta University of Technology 2003.

[105] Rick S, Felden M, Hombitzer M, Hameyer K. Permanent magnet synchronous reluctance machine bridge design for two-layer applications. 2013 Int. Electr. Mach. Drives Conf., IEEE; 2013, p. 137683. doi:10.1109/IEMDC.2013.6556316.

[106] Bianchi N, Bolognani S, Bon D, Dai Pre M. Torque Harmonic Compensation in a Synchronous Reluctance Motor. IEEE Trans Energy Convers 2008;23:466-73. doi:10.1109/TEC.2007.914357.

[107] Carraro E, Degano M, Bianchi N. Permanent magnet volume minimization in permanent magnet assisted synchronous reluctance motors. 2013 8th Int. Conf. Exhib. Ecol. Veh. Renew. Energies, EVER 2013, IEEE; 2013, p. 1-4. doi:10.1109/EVER.2013.6521539.

[108] Kaiser Motoren n.d. http://www.kaiser-motoren.de/downloads/Produktprospekt-Kaiser-Motoren.pdf (accessed November 29, 2015). 
[109] ABB. Low voltage IE4 synchronous reluctance motor and drive package 2015:1-44.

[110] REEL - Product \& Services - Product catalogue n.d. http://www.ksb.com/REELen/Product_and_services/Product_catalogue__/ (accessed November 29, 2015).

[111] Ricardo develops next-generation electric vehicle motor - Ricardo n.d. http://www.ricardo.com/enGB/News--Media/Press-releases/News-releases1/2015/Ricardo-develops-next-generation-electricvehicle-motor-/ (accessed November 29, 2015).

[112] Ooi S, Morimoto S, Sanada M. Performance evaluation of a high power density PMASynRM with ferrite magnets. 2011 IEEE Energy Convers. Congr. Expo., IEEE; 2011, p. 4195-200. doi:10.1109/ECCE.2011.6064341.

[113] Obata M, Morimoto S, Sanada M, Inoue Y. Performance evaluation of high power and low torque ripple structure of rare-earth free PMASynRM with ferrite magnet. Proc. Int. Conf. Power Electron. Drive Syst., IEEE; 2013, p. 714-9. doi:10.1109/PEDS.2013.6527111.

[114] Niazi P. Permanent magnet assisted synchronous reluctance motor, design and performance improvement. Texas A\&M University 2006.

[115] Chakali AK. Sensorless Speed Control of Permanent Magnet-Assisted Synchronous Reluctance Motor (PMa-SynRM). Texas A\&M University 2011.

[116] Sanada M, Inoue Y, Morimoto S. Structure and characteristics of high-performance PMASynRM with ferrite magnets. Electr Eng Japan (English Transl Denki Gakkai Ronbunshi) 2014;187:42-50. doi:10.1002/eej.22362.

[117] Obata M, Morimoto S, Sanada M, Inoue Y. Performance of PMASynRM with ferrite magnets for EV/HEV applications considering productivity. IEEE Trans Ind Appl 2014;50:2427-35. doi:10.1109/TIA.2013.2294999.

[118] Lee JH, Lee IK, Jeon AR. Efficiency evaluation of PMASynRM vs. SynRM using coupled FEM \&Preisach modeling. 2010 Int. Conf. Electr. Mach. Syst., IEEE; 2010, p. 1425-8.

[119] Kim K-C, Ahn JS, Won SH, Lee J. A Study on the Calculation and Reduction Method of Torque Ripple for Permanent Magnet Assisted Synchronous Reluctance Motor by using the Load Angle Curves. 2006 12th Bienn. IEEE Conf. Electromagn. F. Comput., IEEE; n.d., p. 76-76. doi:10.1109/CEFC-06.2006.1632868.

[120] Pellegrino G, Vagati A, Boazzo B, Guglielmi P. Comparison of Induction and PM Synchronous Motor Drives for EV Application Including Design Examples. IEEE Trans Ind Appl 2012;48:232232. doi:10.1109/TIA.2012.2227092.

[121] Dorrell DG, Knight AM, Evans L, Popescu M. Analysis and Design Techniques Applied to Hybrid Vehicle Drive Machines-Assessment of Alternative IPM and Induction Motor Topologies. IEEE Trans Ind Electron 2012;59:3690-9. doi:10.1109/TIE.2011.2165460.

[122] Mishra P, Saha S. Design modeling and simulation of low voltage squirrel cage induction motor for medium weight electric vehicle. 2013 Int. Conf. Adv. Comput. Commun. Informatics, IEEE; 2013, p. 1697-704. doi:10.1109/ICACCI.2013.6637437.

[123] Chiba K, Takemoto M, Chino S, Ogasawara S. Fundamental Analysis of a Ferrite Permanent Magnet Axial Gap Motor with Coreless Rotor Structure. IEEJ J Ind Appl 2013;3:47-54. doi:10.1541/ieejjia.3.47.

[124] Chino S, Ogasawara S, Miura T, Chiba A, Takemoto M, Hoshi N. Fundamental characteristics of a ferrite permanent magnet axial gap motor with segmented rotor structure for the hybrid electric 
vehicle. IEEE Energy Convers. Congr. Expo. Energy Convers. Innov. a Clean Energy Futur. ECCE 2011, Proc., IEEE; 2011, p. 2805-11. doi:10.1109/ECCE.2011.6064146.

[125] Liu Y, Zhao J, Wang R, Huang C. Performance improvement of induction motor current controllers in field-weakening region for electric vehicles. IEEE Trans Power Electron 2013;28:2468-82. doi:10.1109/TPEL.2012.2217757.

[126] Watterson P a., Wu WWW, Kalan B a., Lovatt HC, Prout G, Dunlop JB, et al. A switched-reluctance motor/generator for mild hybrid vehicles. 2008 Int Conf Electr Mach Syst 2008:2808-13.

[127] Hennen MD, Niessen M, Heyers C, Brauer HJ, De Doncker RW. Development and control of an integrated and distributed inverter for a fault tolerant five-phase switched reluctance traction drive. Proc. 14th Int. Power Electron. Motion Control Conf. EPE-PEMC 2010, vol. 27, IEEE; 2010, p. S11-7 - S11-24. doi:10.1109/TPEL.2011.2132763.

[128] Kiyota K, Sugimoto H, Chiba A. Comparison of energy consumption of SRM and IPMSM in automotive driving schedules. 2012 IEEE Energy Convers. Congr. Expo. ECCE 2012, IEEE; 2012 , p. 853-60. doi:10.1109/ECCE.2012.6342729.

[129] Kiyota K, Kakishima T, Chiba A. Comparison of test result and design stage prediction of switched reluctance motor competitive with $60-\mathrm{kW}$ rare-earth PM motor. IEEE Trans Ind Electron 2014;61:5712-21. doi:10.1109/TIE.2014.2304705.

[130] Takeno M, Chiba A, Hoshi N, Ogasawara S, Takemoto M, Rahman MA. Test results and torque improvement of the 50-kw switched reluctance motor designed for hybrid electric vehicles. IEEE Trans Ind Appl 2012;48:1327-34. doi:10.1109/TIA.2012.2199952.

[131] Huppunen J. High-speed solid-rotor induction machine - electromagnetic calculation and design. Lappeenranta University of Technology (Finland), 2004.

[132] Pyrhonen J, Jokinen T, Hrabovcova V. Design of Rotating Electrical Machines, 2nd Edition -. 2nd Editio. Chichester, West Sussex, UK: John Wiley \& Sons Ltd; 2013.

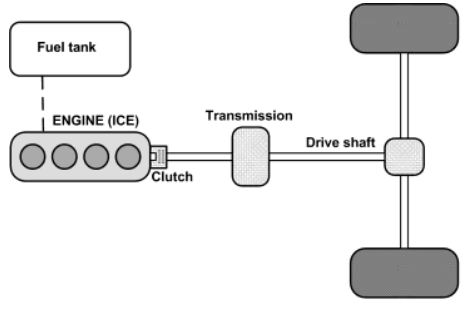

a) ICE vehicle

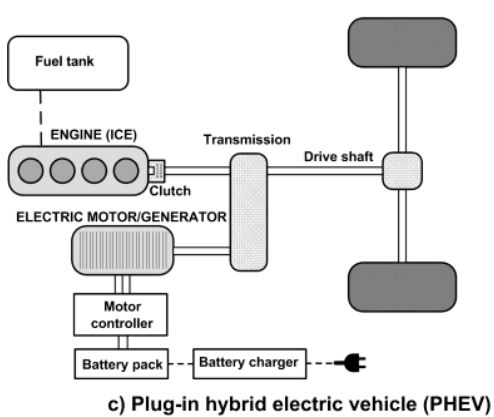

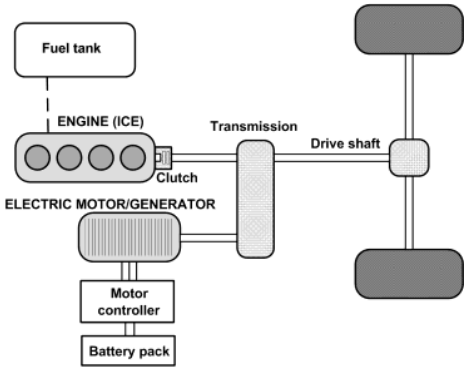

b) Parallel hybrid electric vehicle (HEV)

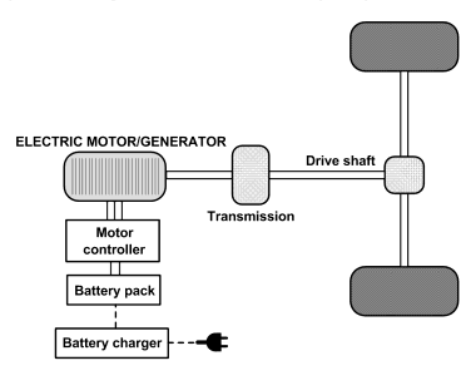

d) Full electric vehicle (FEV)

Fig. 1. Configurations of different vehicle types 


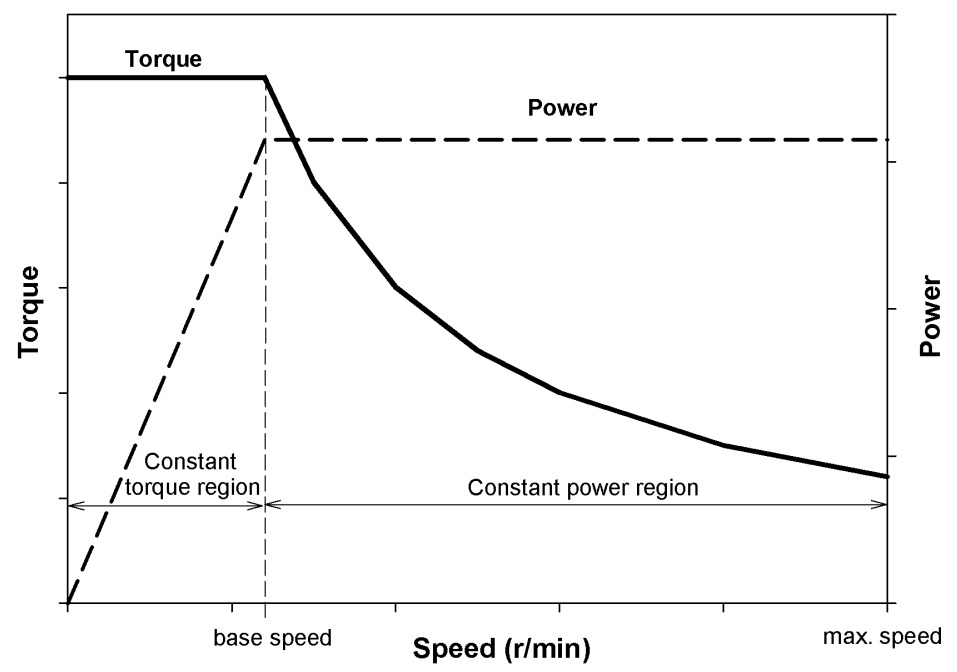

Fig. 2. Torque-speed and power-speed characteristics for a typical traction electric motor

\section{Brushless motors for EVs propulsion systems}

\section{Asynchronous}

- Cage Induction Motor
Synchronous

- SPMSM and IPMSM

- Switched Reluctance Motor

- Wounded Field Flux Switching Motor

- PM Flux Switching Motor

- Hybrid Flux Switching Motor

- Synchronous Reluctance Motor

- PMa-Synchronous Reluctance Motor

Fig. 3. Motors types analyzed in this work for EV applications.

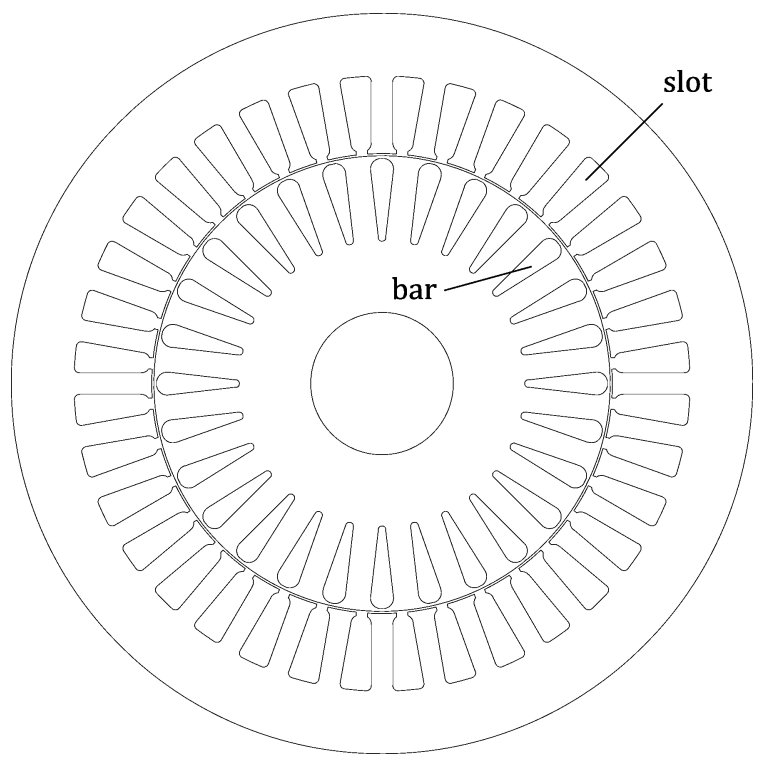

Fig. 4. Cross-section of a squirrel cage induction motor (SCIM). 

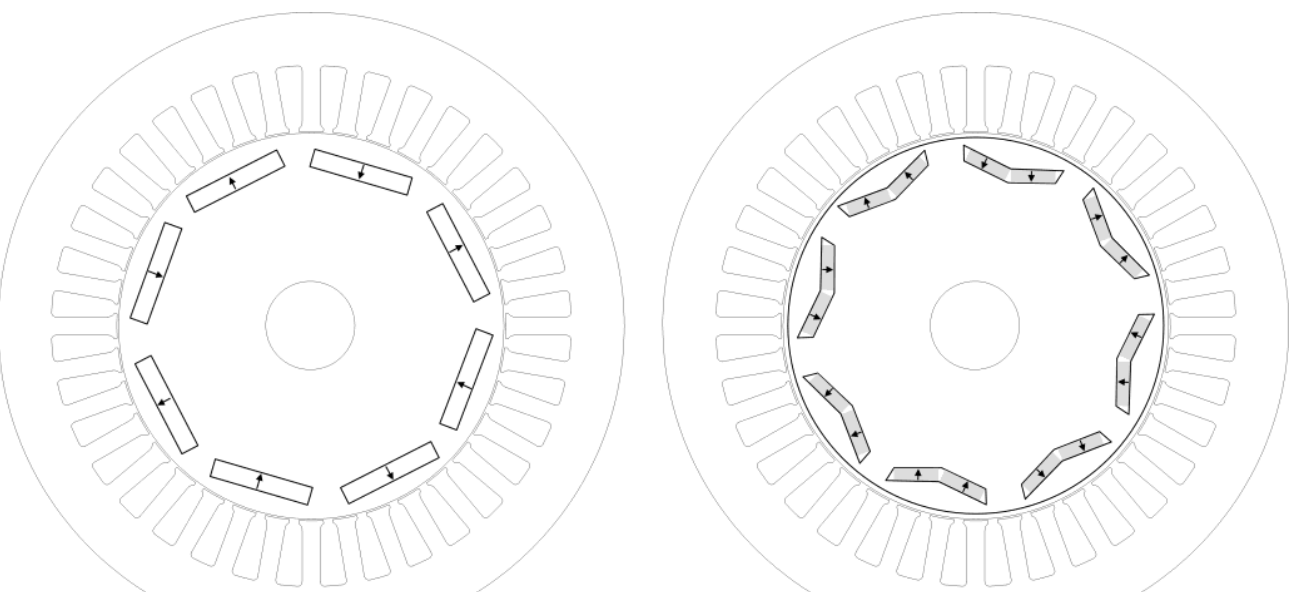

Fig. 5. Cross-section of a radial flux interior PM motor with tangentially and V shaped embedded PMs.

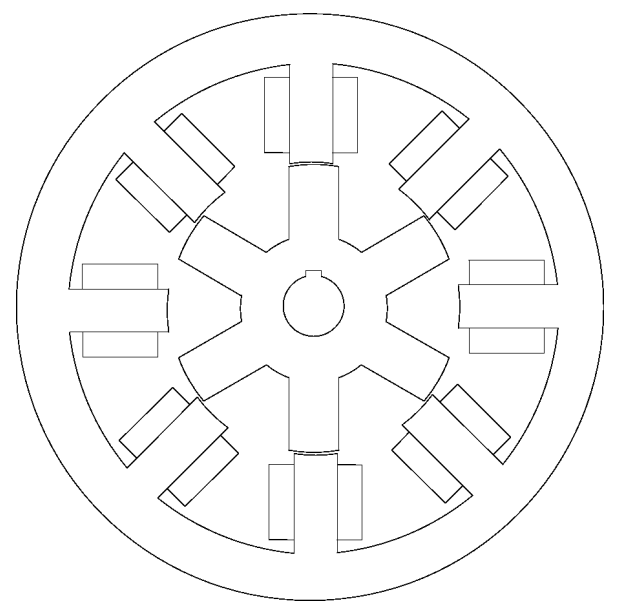

Fig. 6. Basic geometry of a four-phase 8/6 SRM.
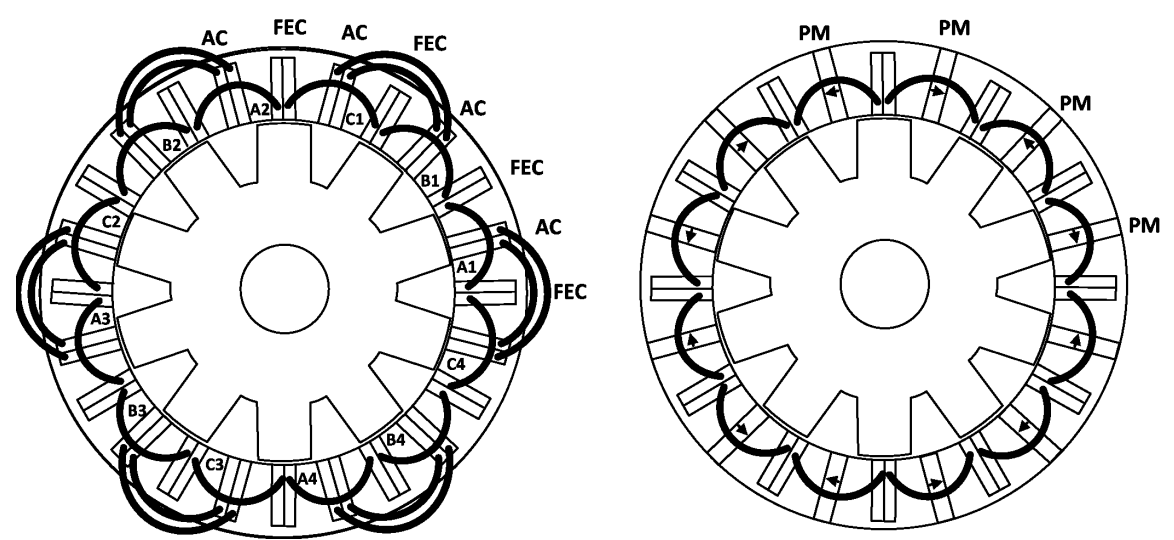

Fig. 7. Cross-section of a WFFSM and a PMFSM, where FEC stands for the DC field coil whereas AC stands for the three-phase AC armature coil. 

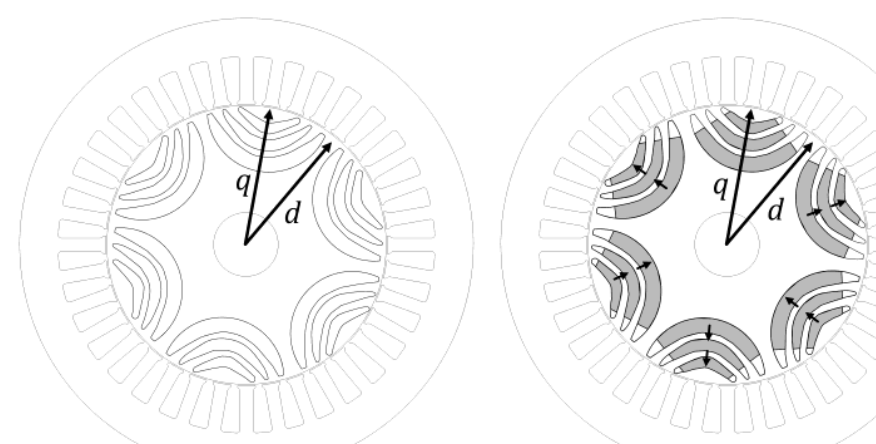

Fig. 8. Structures of a SynRM and a PMa-SynRM.

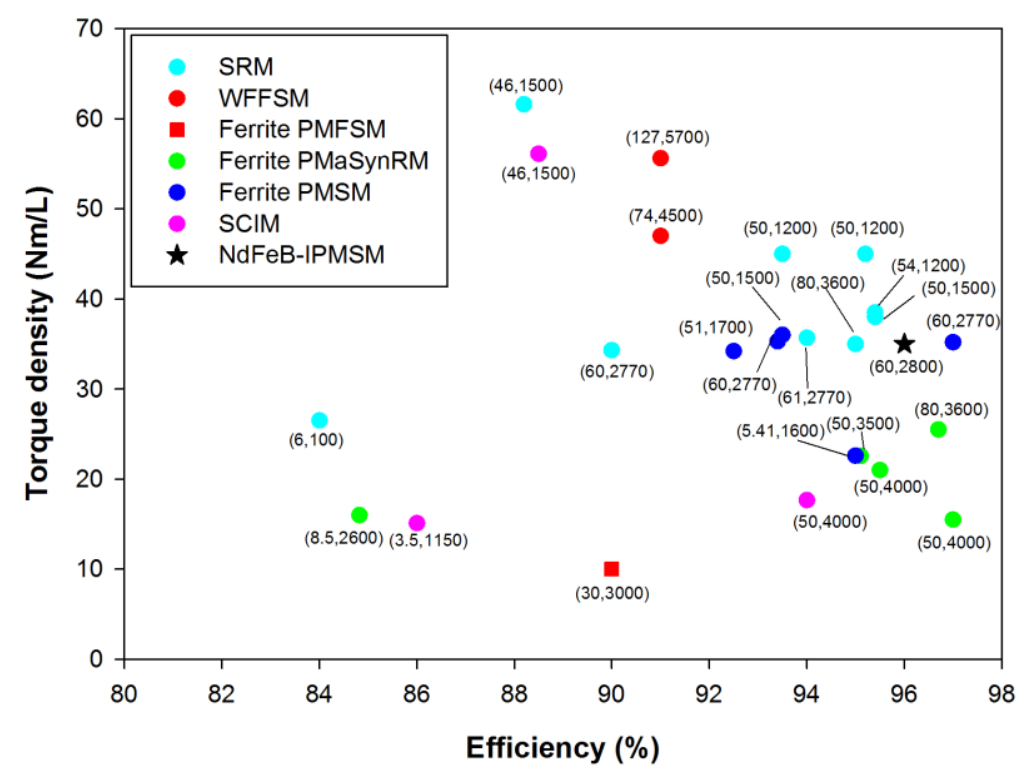

Fig. 9. Machines comparison based on the maximum efficiency point and torque density calculated at the flat rated torque. Data presented have been collected from $[57,62,68,69,71,72,74,76,77,83,90,100,113,117,120-130]$. Parenthesis indicate the mechanical output power and base speed, respectively, in ( $\mathrm{kW}, \mathrm{r} / \mathrm{min})$. 


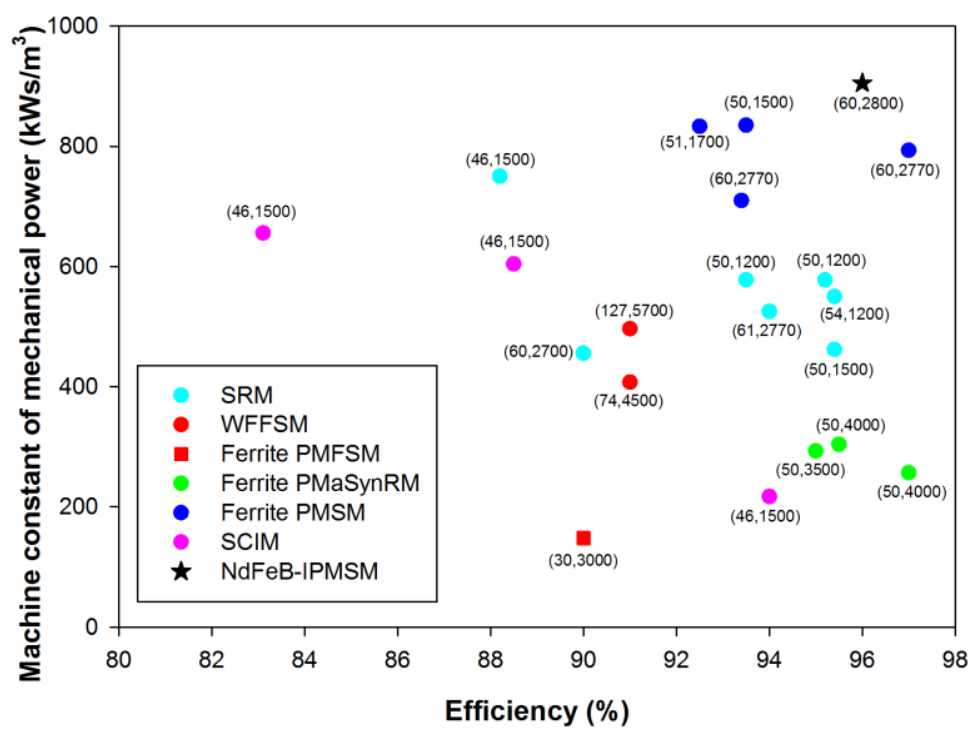

Fig. 10. Machines comparison based on the maximum efficiency point and machine constant of mechanical power. Data presented have been collected from [57,62,68,69,72,74,76,77,83,90,100,113,117,120126,128-130]. Parenthesis indicate the mechanical output power and base speed, respectively, in (kW,r/min).

Table 1. Properties of PM materials.

\begin{tabular}{ccccc}
\hline Property & Alnico & Ferrites (ceramic) & $\begin{array}{c}\text { Samarium cobalt } \\
\mathbf{1 - 5} \text { and 2-17 alloys }\end{array}$ & $\begin{array}{c}\text { Neodymium } \\
\text { Nd(Pr,Dy) (Fe,Co,Hf)B }\end{array}$ \\
\hline $\begin{array}{c}\text { Residual induction } \\
(\mathrm{Br}, \mathrm{T})\end{array}$ & $0.7-1.28$ & $0.23-0.41$ & $0.83-1.16$ & $1.00-1.41$ \\
$\begin{array}{c}\text { Coercitive force }\left(H_{c},\right. \\
\mathrm{kA} / \mathrm{m})\end{array}$ & $37-143$ & $50-290$ & $480-840$ & $760-1030$ \\
$\begin{array}{c}\text { Max. energy product, } \\
(B H)_{\max }, \mathrm{kJ} / \mathrm{m}^{3}\end{array}$ & $10.7-71.6$ & $8.35-31.8$ & $130-240$ & $220-366$ \\
$\begin{array}{c}\text { Electric resistivity, } \rho, \\
\quad 5 \cdot \mathrm{cm}^{-6}\end{array}$ & $10-75 \cdot 10^{-6}$ & $10^{6}$ & $53-86 \cdot 10^{-6}$ & $160 \cdot 10^{-6}$ \\
$\quad \begin{array}{l}\text { Max. service } \\
\text { temperature, } T_{\max },{ }^{\circ} \mathrm{C} \\
\text { Density, } d, \mathrm{~g} / \mathrm{cm}^{3}\end{array}$ & $450-550$ & 800 & $300-350$ & 150 \\
\hline
\end{tabular}


Table 2. Electric motor drives comparison

\begin{tabular}{|c|c|c|c|c|}
\hline & Brushed DC & IM & PMSM & SRM \\
\hline \multicolumn{5}{|c|}{ Adapted from [44] } \\
\hline Efficiency & 2.0 & 4.0 & 5.0 & 4.5 \\
\hline Weight & 2.0 & 4.0 & 4.5 & 5.0 \\
\hline Cost motor & 5.0 & 4.0 & 3.0 & 4.0 \\
\hline TOTAL & 9.0 & 12.0 & 12.5 & 13.5 \\
\hline \multicolumn{5}{|c|}{ Adapted from [52] } \\
\hline Power density & 2.5 & 3.5 & 5.0 & 3.5 \\
\hline Efficiency & 2.5 & 3.5 & 5.0 & 3.5 \\
\hline Controllability & 5.0 & 5.0 & 4.0 & 3.0 \\
\hline Reliability & 3.0 & 5.0 & 4.0 & 5.0 \\
\hline Technol. maturity & 5.0 & 5.0 & 4.0 & 4.0 \\
\hline Cost & 4.0 & 5.0 & 3.0 & 4.0 \\
\hline TOTAL & 22.0 & 27.0 & 25.0 & 23.0 \\
\hline
\end{tabular}

